\title{
Novel COVID-19 Pandemic Scenario: A Review of the Current Literature
}

\author{
Anilkumar V ${ }^{1 *}$, Murali Krishna $\mathbf{B}^{2}$, Sangeeta Kumari $\mathrm{L}^{3}$ and Kalyani $\mathbf{R}^{2}$ \\ ${ }^{1}$ Assistant Professor, Department of Pharmaceutical Technology, GIET School of \\ Pharmacy, Rajahmundry, East Godavari, Andhra Pradesh, India \\ ${ }^{2}$ Assistant Professor, Department of Pharmaceutical Technology, Sri Venkateswara \\ College of Pharmacy, Etcherla, Srikakulam, Andhra Pradesh, India \\ ${ }^{3}$ Assistant Professor, Department of Pharmaceutical Analysis and Quality Assurance, \\ Raghu College of Pharmacy, Dakamarri, Visakhapatnam, Andhra Pradesh, India \\ *Corresponding Author: Anilkumar V, Assistant Professor, Department of \\ Pharmaceutical Technology, GIET School of Pharmacy, Rajahmundry, East Godavari, \\ Andhra Pradesh, India.
}

DOI: $10.31080 /$ ASPS.2020.04.0561
Received: June 22, 2020

Published: July 09, 2020

(C) All rights are reserved by Anilkumar V., et al.

\begin{abstract}
The Pandemic which COVID-19 has made on the Globe needs no depiction. The disease caused by SARS-COV-2 presents flu-like symptoms which can be become serious in high-risk individuals. In this review article we provide an overview of the symptoms, treatment, diagnostic tools, drugs usages, vaccine trials options for Novel COVID-19. We carried out a systematic literature search using the main online databases like Google scholar, PUBMED, Medscape daily News by using keywords like COVID-19, corona virus. We included different publications from last six months data which focused clinical features and treatment. We found entry mechanism of virus into the body, Hand hygiene is key factor to prevent contamination, wear gloves in specified situations. The amin symptoms of COVID-19 are cough, fever, fatigue, slight dyspnea etc. RT-PCR, LAMP, ELISA is used as an analytical instrument utilizing Nasal swab, tracheal suction or bronchoalveolar lavage tests. The primary treatment being used to treat the infection are antibiotics, antiviral drugs like chloroquine. Therefore this review article main theme is focusing on many treatments have been proposed, self quarantine, isolation is the main medication that seems, by all accounts to be powerful in decreasing virus rate specifically designed randomized clinical trials are excepted to determine the most appropriate evidence-based treatment methodology more research work to be carried out to provide more reliable and valid effect to control and mange public emergency in both acute and chronic conditions of coronavirus.
\end{abstract}

Keywords: COVID-19; Pandemic; RT-PCR; LAMP; ELISA; Prevention; SARS-COV-2; Literature; Medscape; Google Scholar

\section{Introduction}

The Novel corona virus disease-19 (COVID-19) is a profoundly transmittable and pathogenic viral disease brought about by serious acute respiratory syndrome corona virus-2 (SARS-CoV-2). Genomic examination uncovered that SARS-CoV-2 is photo genetically identified with severe acute respiratory syndrome-like(SARSlike) bat infection, along these lines bats could be the conceivable primary reservoir, Corona represents crown-like spike on the outer surface of the virus. thus, it was named as corona virus. Recently at the end of 2019, Wuhan. An emerging business hub of china experienced an outbreak of a novel corona virus this virus was reported to be a member of the beta group of corona viruses. It shows that the transmission rate of SARS-CoV-2 is higher than SARS-CoV and the reason could be genetic recombination event at $S$ protein in the RBD (Recent Binding Domain) region of SARS-COV-2 may have enhanced its transmission ability [1]. The new COVID-19 has become a worldwide health danger up to $15^{\text {th }}$ June 2020, COVID-19 has caused the deaths more than four lakhs and worldwide effected persons more than seventy lakhs. It shows flu-like symptoms like fever, cough, cold etc. Although serious lung injury has been portrayed at all ages, in some high-risk in old people, the virus is more likely to cause extreme intestinal pneumonia, acute respiratory distress syndrome (ARDS) and resulting multiorgan failure, which are liable for serious acute respiratory failure and death rates, here, we summarized the present available information on the clinical highlights and treatment choice for COVID-19 [2]. 
Morphology of corona virus: Corona virus are large pleomorphic spherical particles with bulbous surface projection the diameter of the virus particles is around $120 \mathrm{~nm}$. The viral envelope consists of lipid bilayer membrane, spike structural proteins are anchored, the positive -sense single-standard RNA genome in a continuous beads on a string type conformation. The genome size for corona viruses ranges from approximately 27 to 34 kilobases [3,4].

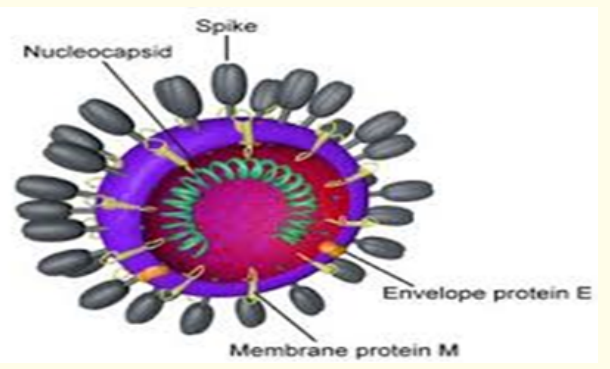

Figure 1: Corona virus.

\section{Methods}

By using the Web databases, we completed a precise writing review of the clinical symptoms, prevention and management of Novel COVID-19. Main key review and research articles were recovered mainly from web sources like Google, Google scholar, MEDLINE, Wiley library, MEDSPACE, etc. Utilizing term like novel COVID-19, pandemic COVID-19, SARS-COV-2, keywords for our search. Only publications focusing on clinical attributes of and medicine's for SARS-CoV-2 were qualified for consideration. In an uncommon exertion, hundreds of thousands of scientists and researchers worldwide are locked in a race against time to develop antibodies, drugs, vaccines and better diagnostic tests for COVID-19, the disease caused by the virus SARS-COV-2. All searches as well as title and abstract, screening and study choice were performed. All articles esteemed possibly qualified were recovered for text reviews.

Epidemiology

In December 2019, numerous Pneumonia cases that were bunched in Wuhan city were accounted for and looks for the source have indicated Wuhan seafood markets as the starting point. The principal instance of the COVID-19 epidemic was found with unexplained pneumonia on December 12, 2019 and 27 viral pneumonia cases with seven being extreme, were officially reported on last date of December 2019. Etiologic examination have been acyted in patients who applied to the medical clinical because of comparable viral chronicles of these patients has fortified the probability of a contamination transmitted from creatures to people. On January 22, 2020. Novel CoV has been proclaimed be begun from wild bats and had a place with Group 2 of beta-coronavirus that contains severe acute respiratory syndrome associated coronavirus (SARSCoV).

Despite the fact that COVID-19 and SARS-COV have a place with similar beta corona infection subgroup, comparability at genome level is just $70 \%$ and the novel gathering has been found to show hereditary contrasts from SARS-CoV, like the SARS epidemic this spring festival in China, which is the most well known customary celebration in China, during which about 3 billions people travel country wide. These conditions caused positive conditions for the transmission of this exceptionally infections ailments and extreme challenges in counteraction and control of epidemic. The time of the spring of festival of China was between January 17 and February 23 out of 2003, when the SARS epidemic crested, while the time of the celebration was between January 10 and February 18 out of 2020. Additionally, there was a fast increment in COVID-19 cases between January $10-22$. Wuhan, the focal point of the epidemic with 10 million population, is like wise a significant focus in the spring celebration transportation network. The evaluated number of explores during the 2020 spring celebration has risen 1.7 folds when contrasted and the number went in 2003 and came to 3.11 billion from 1.82 billion. This enormous scope travel traffic has like wise made good conditions for the spread of this hard to control disease.

Comparison of epidemiological characteristics between SARSCOV, SARS-COV-2 and MERS-CoV:

- $\quad$ SARS-COV (Severe acute respiratory syndrome- coronavirus): Transmission mode: Human to human through aerosol droplets, oral transmission, Zoonotic, fecal, airborne transmission.

- Host of virus: Chinese horseshoe bats are natural hosts, masked palm civets and human incubation period is 4 days.

- SARS-COV-2: Transmission mode is Human to human through aerosol droplets, Physical contact, Zoonotic transmission. Incubation period 6/4 days (range 0 to 24 days) Host of virus is Bats are natural hosts etc.

- $\quad$ MERS-CoV: Respiratory transmission, Zoonotic, aerosol, limited human to human transmission. Hosts is Bats are natural hosts, dromedary camels are intermediate hosts, incubation period is 5 days [5-7]. 
Pathophysiology

The specific pathophysiology of the infection is obscure yet however basic examination that it might be influence by official with ACE-2 receptor in people which proposes that it might have comparable system as of SARS-CoV. The hereditary material for example RNA is encircled by the protein envelope which have protein Spike on it. These infection virus join to human cell, at that point experience an auxiliary change and in light of that the viral film append with the cell layer. The viral qualities at that point go into the host cell to be replicated to deliver more viruses. Recent work shows that, similar to the infection that caused the 2003 SARS outbreaks, SARS-COV-2 spike tie to receptors on the human cell surface called angiotensin-converting enzyme-2 (ACE-2). A Turin like cleavage site has been recognized in spike protein of virus which doesn't exist in different SARS like crown spike coronavirus [8,9].

\section{Routes of transmission}

SARS-COV-2 infection normally spread through respiratory droplets or contact. Therefore, coughing or sneezing by an infected person can render SARS-COV-2 airborne, possibly tainting people in close contact (approximately $6 \mathrm{ft}$ distance). This promoted maintained social distance to minimize spread of infection, another route for spreading infection is if droplets of SARS-COV-2 land on lifeless things found close by a tainted individuals. Hence, Hand washings and other disinfected objects are essential for ending the spread vof this disease. This suggestions is fortified thinking about that individuals contact their face on a normal 23 times each hour, with $44 \%$ of these events including the mucous membranes of the nose or mouth. As per other studies have shown the presence of SARS-COV-2 in both saliva and fecal matter of the affected patients. It known that SARS-COV-2 can bind to human Angkor ending converting enzyme 2 receptor, which are highly concentrated in salivary glands. Therefore, there is a potential for transmission COVID-19 via aerosol, fomites or the fecal-oral route that may add to nosocomial spread [10-12].

\section{Entry mechanism of novel COVID-19}

All corona viruses contains explicit genes in ORF1 downstream regions that encode proteins for nucleocapsid, viral replication and splines arrangement. The glycoprotein spikes on the external surface of corona virus are liable for the connection and section of the infection to host cells. Different corona viruses generally perceive aminopeptidases or carbohydrates as a key receptor for passage to human cells while SARS-COV. The entry mechanism of corona virus depends upon cellular professes which incorporate, human airway trypsin-like protease (HAT), Cathepsins and trans membrane protease serine2 (TMPRSS2) that split the spike protein and set up further entrance changes. SARS-COV require an Angkor ending converting enzyme 2 (ACE2) as a key receptor. SARS-COV-2 has the ordinary corona virus structure with spike protein and furthermore communicated different poly proteins, membrane proteins and nucleoproteins. The spike protein of SARS-COV-2 contains a 3-D structure in the RBD area to keep up the Vander Waals forces [13-16].

\section{Life cycle of coronavirus}

Life cycle of coronavirus has 4 steps of viral life in human:

- Attachment and entry

- Transmission of replicase gene from viral RNA

- Replication and transcription

- $\quad$ Assembly and release $[17,18]$.

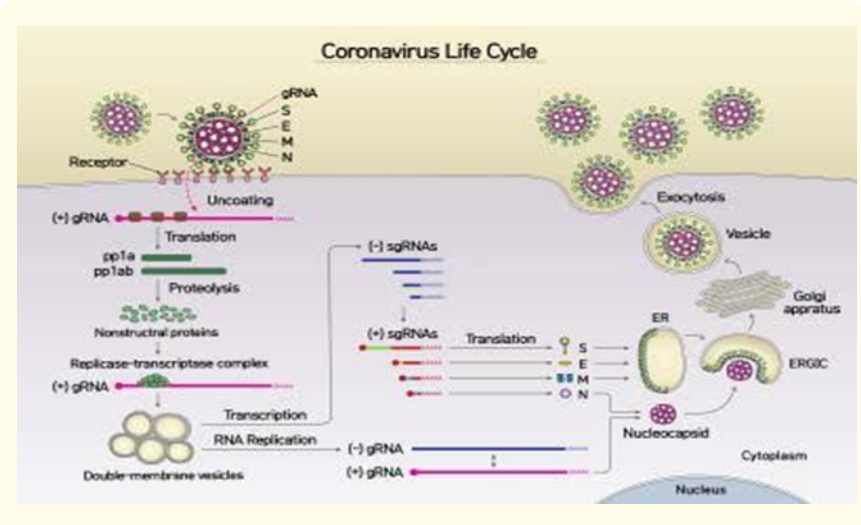

Figure 2: Image of coronavirus life cycle.

\section{Symptoms}

Dry cough, Running nose, High fever, Shortness of breath, Headache, Nausea, vomiting, sore throat, Pneumonia, Digestive system disorder, Cardiac shock, Rhinorrhoea, Muscle ache, Acute real injury [19].

\section{Diagnosis [20-23]}

The SARS-COV-2 infected patients have sign and symptoms such as dry cough, cold, fever, fatigue, dyspnea etc. with or without nasal congestion. Despite the atypical symptoms recorded and fever is still the typical symptom of SARS-COV-2., for the identification of viruses use real time reverse transcription polymerase chain reaction (RT-PCR), Loop-mediated isothermal amplification(LAMP), Lateral flow/Colloidal Gold Immune chromatography, Enzymelinked Immunosorbent Assay (ELISA). 


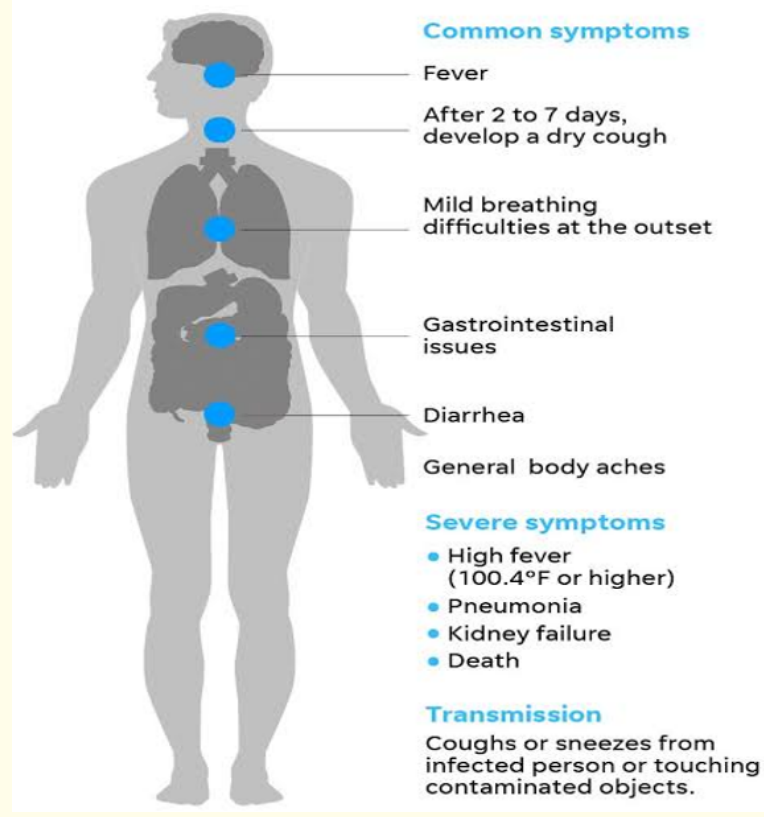

Figure 3: Image of coronavirus symptoms.

Reverse-transcription polymerase chain reaction (RT-PCR): PCR is a very common scientific technique that has been widely used in research and medicine for around 20 - 30 years to detect genetic information. RT-PCR is a special version used when RNA is being detected and it is now being used as a test to detect SARSCoV-2, the virus causing COVID-19. This type of test has frequently been used as a frontline test for COVID-19 as it directly tests for the presence of the virus RNA. RT-PCR tests are fairly quick, sensitive and reliable, capable of producing results in 3 - 4 hours, although this usually takes longer if samples must first be sent to specialized external laboratories (6 - 8 hours on average). Many diagnostic and research companies produce RT-PCR products, tests and machines so the technology is widely available. Some RT-PCR tests are developed as an 'all in one' kit, reducing laboratory handling and potential for contamination

Loop-mediated isothermal amplification (LAMP): Loop-mediated Isothermal Amplification (LAMP) is a similar process to RT-PCR, but instead of using a series of temperature changes to produce copies of the viral DNA, LAMP is conducted at a constant temperature of $60-65^{\circ} \mathrm{C}$. The amount of DNA produced in LAMP is much higher than in RT-PCR and a positive test result can be seen visually without requiring a machine to read the results. LAMP is a newer technique compared to RT-PCR, but is technically simple and easy for a trained scientist to perform, making it a potentially useful technique for detection of COVID-19. As it is a newer technology, there is less evidence on its use, but diagnostic companies are currently performing clinical trials to support it.

Lateral flow/colloidal gold immunochromatography: Lateral flow assays have commonly been referred to as 'Antibody tests' in the media as they are currently used to detect antibodies to disease in a patient's blood. The technology is also being tested for antigen use too. Lateral flow assays use the same technology commonly used for pregnancy tests. Lateral flow tests can detect antibody to virus from patient blood indicating that the patient has COVID-19 or has recovered from COVID-19. Less commonly, lateral flow tests can be used to detect the presence of active virus by detecting virus proteins directly. Antibody lateral flow tests for SARS-CoV-2 are produced as test kits used by a specialist or clinician rather than by patients themselves. They require a drop of patient blood, either from a vein or from a small finger prick, similar to a finger prick test used for blood sugar monitoring in certain types of diabetes. These types of tests work very differently to RT-PCR and LAMP techniques and detect the patient's immune antibody response to the virus rather than detecting the virus itself. Lateral flow antibody tests can be completed rapidly and the tests can be produced cheaply, so multiple diagnostics companies are working hard to develop lateral flow tests for SARS-CoV-2. A major advantage for this type of test is also the ability to see if patients are currently infected or have recovered from COVID-19 even if they have fully recovered and cleared the virus months ago. However, it cannot distinguish between an active and a previous infection.

Enzyme-linked immunosorbent assay (ELISA): An EnzymeLinked Immunosorbent Assay (ELISA) is a common biochemical technique that can be used to detect antigens or antibodies, depending on the type of test used. ELISAs use enzymes linked to antibodies that can attach to the molecule that is being tested for and cause a colour change that can be measured by a specialised machine. The strength of the colour change gives scientists and clinicians an idea of the number of molecules of interest in the sample. ELISAs can be done as standard batches of up to 96 assays completed at the same time, allowing cheap and time effective method for batch testing of large numbers of patient samples at the same time. This technology could help speed up the number of patients that can be tested for SARS-CoV-2. The most effective ELISA assays in monitoring prior infection detect antibodies against SARS-CoV-2. Future ELISA could be used to test for active virus infection by detection of virus protein (antigen) testing, but this testing will not be as accurate and is as yet unproven. 


\begin{tabular}{|c|c|c|c|}
\hline Method & Characteristics & Test time & Application \\
\hline Antigen EIA & Rapid, poor sensitivity, some are CLIA - waived & $<30 \min$ & Diagnosis (detection) \\
\hline Antigen IFA & $\begin{array}{l}\text { Good sensitivity and specificity, subjective } \\
\text { interpretation }\end{array}$ & $1-4 \mathrm{hrs}$ & Diagnosis (detection) \\
\hline Cell culture & $\begin{array}{l}\text { Gold standard, pure culture for further research- } \\
\text { ing and development, time consuming }\end{array}$ & 1 - 7 days & $\begin{array}{c}\text { Diagnosis, (detection, typing, differentiation) } \\
\text { and research }\end{array}$ \\
\hline Serology & Retrospective, cross section & $2-8 \mathrm{hrs}$ & $\begin{array}{l}\text { Infection confirmation, epidemiology, } \\
\text { vaccine evaluation }\end{array}$ \\
\hline $\begin{array}{l}\text { NAAT, monoplex, Pan } \\
\text { - HCoV }\end{array}$ & $\begin{array}{l}\text { High sensitivity with universal coverage of all } \\
\text { specific of } \mathrm{HCoV}\end{array}$ & $1-8 \mathrm{hrs}$ & $\begin{array}{l}\text { Diagnosis (detection), discovery and } \\
\text { research }\end{array}$ \\
\hline $\begin{array}{l}\text { NAAT, Monoplex, } \\
\text { Specific HCoV }\end{array}$ & $\begin{array}{l}\text { High sensitivity and specificity for species, } \\
\text { potential quantification }\end{array}$ & $1-8 \mathrm{hrs}$ & $\begin{array}{c}\text { Diagnosis (detection), differentiation, limited } \\
\text { typing and research }\end{array}$ \\
\hline NAAT, multiplex & $\begin{array}{l}\text { High sensitivity and specificity, covering other } \\
\text { pathogens film array RPEZ is CLIA - waived }\end{array}$ & $1-8 \mathrm{hrs}$ & $\begin{array}{c}\text { Diagnosis (detection), differentiation, limited } \\
\text { typing) and research }\end{array}$ \\
\hline NAAT, POCT & $\begin{array}{l}\text { Rapidly safe, good sensitivity, specificity, some } \\
\text { are CLIA - waived }\end{array}$ & $\begin{array}{c}15-30 \\
\min \end{array}$ & $\begin{array}{c}\text { Diagnosis (detection), limited differentiation } \\
\text { and research }\end{array}$ \\
\hline
\end{tabular}

Table 1: Laboratory techniques for detection of corona virus [24].

Basic primary prevention [25]

Patients and familiar should receive instruction to:

- Clean your hands regularly, either by washing them with cleanser and water at least 20 seconds or use a $60 \%$ alcohol based hand sanitizer.

- To protect yourself as well as other people, you ought to consistently wash your hands, after handling pets, during and after cooking, after using the washrooms and toilets, before eating, after sneezing or coughing and wash your hands regularly as conceivable when you are sick or caring for the sick.

- Cover your nose and mouth with your elbow if you cough or sneeze, avoid touching your nose and mouth and eyes with your hands because mucous membrane that can act as pathways for particles and our hands are the essential bearer of those harmful liquid particles.

- Frequently wipe your cellphones I.e. screen with a liquor based disinfectant. Try to also maintain voyeur youngsters smart devices like cellphones, tablets as clean as possible.

- Avoid close contact with subjects suffering from acute respiratory infections.

- Don't split in public.

- Immune compromised patients should avoid public exposure and public gatherings. If an immune compromised individual must be in a closed space with multiple individuals present, such as a meeting in a small room, masks, gloves and personal hygiene with antiseptic soap should be undertaken by those in close contact with the individual. In addition, prior room cleaning with antiseptic agents should be undertaken and performed before exposure. Strict personal hygiene measures are necessary for the prevention and control of the is infection.

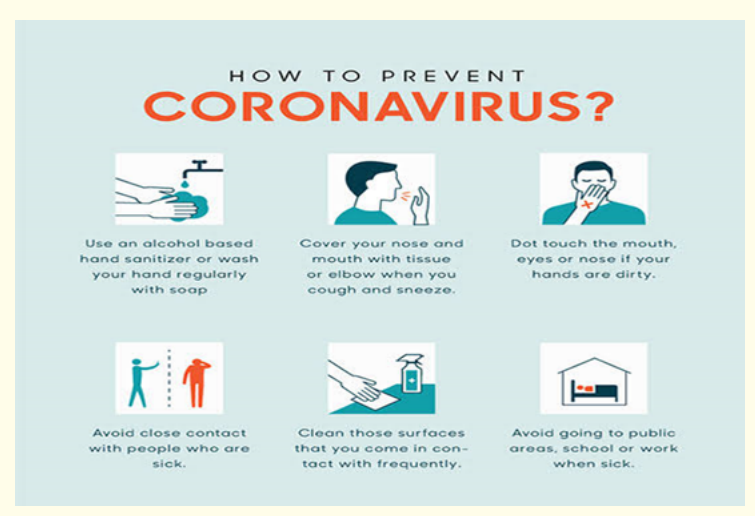

Figure 4: Image of prevention process of corona virus.

Screening and quarantine [26]

- One of the most significant undertaking is to screen the people originating from the endemic territories by checking their temperature, signs and manifestation of virus infection.

- Furthermore, posing inquiries from them about their travel history and any sort of contact with the infected people. 
- $\quad$ There is another idea of collective screening of travelers going through aircrafts after leaving the endemic zones and showing up in some other city/nation, despite the fact that this activity has still not been productive and there are odds of missing over half of the cases of COVID-19, explicitly the Ines who were demonstrating no side effects due to experiencing an incubation period.

- In certain countries, isolate of effectively recognizable people wish signs and symptoms of COVID-19 was done strongly to prevent the further spread of the illness yet the mighty isolate may have ever enduring repercussions with psychosocial impacts.

\section{Medication}

At first, Interferon-alpha nebulization, braid spectrum antibiotics, antiviral drugs were used to reduce the viral load, initially chloroquine and Hydroxy chloroquine widely used, however now Remdesivir has indicated promising effects against the infection. Remedesivir just and in blend with chloroquine or interferon beta fundamentally obstructed the SARS-COV-2 replication and patients were proclaimed as clinically recovered. As well as various antiviral drugs also right now being assessed against infection. Drugs are Ribavirin, Nitazoxanide, Baricitinib, Nafamostat, Favipiravir shows moderate results. When tested against infection in patients and invitro clinical segregates. Several combinations like antibiotics and antiviral will use who showed positive in patients [27-30].

\section{Chloroquine as reposition drugs for SARS-COV-2 emergence}

Chloroquine is perhaps one of the most prescription drugs within the world. Chloroquine is effective in preventing the spread of SARS-COV in cell culture. Favorable inhibition of virus spread was observed when the cells were either treated with chloroquine prior to or after SARS-COV infection. Chloroquine is one of the 4-aminoquinoline antimalarial drugs, chloroquine is weakly basic in nature which accumulates in the acidic vacuoles and has the property to change the $\mathrm{pH}$ of the cell membrane to slightly basic thus prevents the entry of the virus into the host cell and prevents antigen processing and MHC Class II mediated presentation to T cells and ultimately inhibits the replication of virus and acts a fusion inhibition. Chloroquine possess good oral, IM and SC absorption with large volume of distribution and extremely sequestered in the liver, kidney, spleen, lungs and has the capacity to pass the BBM, undergoes hepatic biotransformation and slowly excreted in urine. The drug also requires a close cardiac monitoring while treating COVID-19 associated pneumonia due to its ability to prolong QTc interval, which may lead to fatal arrhythmia and torsade points in COVID-19 patients [31-34].
Interferon therapy may speed recovery from COVID-19

Treatment with the antiviral interferon alfa2b (IFN-a2b) seems to accelerate virus leeway and lower levels of key provocative markers in patient with COVID-19, as per an exploratory investigation directed in Wuhan, China. Interferons are broad antiviral this examination gives the principal convincing proof of a potential treatment that is endorsed. In a paper in frontiers of immunology, Dr. Fish and colleagues report the clinical course of 77 adults with affirmed COVID-19 who were treated with breathed in IFN-a2b, arbidol or the combination of both broad spectrum antivirals. All patients had just moderate sickness, none required serious consideration or oxygen supplementation [35].

Remdesivir shortens COVID-19 time to recovery in published study

Remdesivir is a prodrug of a nucleotide analogue that is intracellularly metabolized to an analogue of adenosine triphosphate that inhibits viral RNA polymerases. Remdesivir has broad-spectrum activity against members of several virus families, including filoviruses and has shown prophylactic and therapeutic efficacy in nonclinical models of these coronaviruses. In vitro testing has also shown that remdesivir has activity against SARS-CoV-2. According to New England Journal of Medicine late Friday suggest Remdesivir shortness the disease course for COVID-19 patients in the study 1063 patients, the researchers found patients who received a 10 days course of Remdesivir had a reduced recovery time of 11 days, compared to 15 days to recovery in the group that received a placebo. FDA says Remdesivir may be effective in treating COVID-19. Drug give administered I.V and the optimal dosing and duration [36-38].

\section{Current clinical trails}

Most of the agents under trial are repurposed for the current COVID-19. Concurrently, the development of vaccines represents a more long term strategy to prevent COVID-19 outbreaks in the future, with the sequencing box SARS-COV-2 genome, multiple nucleic acid-based vaccine candidates have been proposed. Mostly based on the $\mathrm{S}$ protein coding sequence.

Favipiravir treatment approved DCGI for moderate symptoms of COVID-19 patients

Favipiravir is a pyrazine carboxamide derivative with activity against RNA viruses. Favipiravir is converted to the ribofuranosyl triphosphate derivative by host enzymes and selectively inhibits the influenza viral RNA-dependent RNA polymerase. Discovered by Toyama Chemical Co., Ltd. in Japan, favipiravir is a modified pyrazine analog that was initially approved for therapeutic use in resistant cases of influenza. The antiviral targets RNA-dependent 
RNA polymerase (RdRp) enzymes, which are necessary for the transcription and replication of viral genomes. Not only does favipiravir inhibit replication of influenza $A$ and $B$, but the drug has shown promise in the treatment of avian influenza and may be an alternative option for influenza strains that are resistant to neuramidase inhibitors. Favipiravir has been investigated for the treatment of life-threatening pathogens such as Ebola virus, Lassa virus, and now COVID-19 [39-40].

Glenmark was the first company in India to receive the drug regulator's Drugs Controller General of India is a department of the Central Drugs Standard Control Organization of the Government of India approval to conduct phase-3 clinical trial of Favipiravir antiviral tablets for Covid-19 patients on June 20, 2020. Favipiravir used for who are having moderate symptoms COVID-19. It will be available under the brand name FabiFlu as a prescription-based medication for Rs 103 per tablet, with recommended dose of 1,800 mg twice a day on day 1 and $800 \mathrm{mg}$ twice a day up to $14^{\text {th }}$ day. Favipiravir could be used for Covid-19 patients with comorbid conditions, like diabetes and heart disease, the company said and added, it would offer rapid reduction in viral load within four days, and faster symptomatic and radiological improvement $[40,41]$.

\section{COVID-19 vaccine run [42-50]}

Now, Vaccines are not available in the market, but preparation of vaccine against COVID-19 is under process and it may take more than 10 months for the initial sample to get accessibility in the open market. The development of vaccine represented a more long term strategy to prevent COVID-19 outbreaks in the future. With the sequencing of SARS-CoV-2 genome, numerous nucleic corrosive bases immunization up and comer have been proposed generally dependent on the $\mathrm{S}$ protein coding arrangement:

- INO-4800: A DNA immunization applicants made by Inovio Pharmaceuticals, a US based organization. Contrasted with ordinary antibody, hereditary immunization requires Lowe cists of creation and simpler method of cleansing. At present is in Phase-I clinical testing in the US for COVID-19 and !right progree to phase 2 or 3 adequacy trails this mid year.

- mRNA-1273: means Moderns m RNA-1273 is a synthetic strand of mRNA created by masschsettes based US company. Expected to elicit antiviral response specifically towards the spike protein of SARS-CoV-2. Unlike conventional vaccine, does not require the virus. Therefore it is relatively safe and ready to be tested. If mRNA-273 probes to be safe for humans and pass the phase- I trail, successive evaluation of its efficacy will be carried out immediately.
- ChAdoX1nCoV-19: Created by the university of Oxford composed of non-replicating adenovirus vector and the genetic sequence of the S protein of SARS-CoV-2. Entered phase $1 / 2$ clinical trails the non- relatively safe in children and individuals with underlying diseases if the vaccine is shown to be safe and effective in these earlier trails, vaccine manufacturing will be increases to allow larger studies to take place.

- Cure vac: German biotech firm Cure vac has started the firm is using a new technology based on mRNA, a type of genetic material never before used to make a vaccine. The process entails injecting a short sequence of viral genetic material to trigger an immune response by producing proteins acting against the virus.

- BCG vaccine: The Bacillus Calmette Guerin live constricted antibody applicant is in the phase 2 or 3 and is utilized against tuberculosis to support the insusceptible framework. Clinical trails are being conducted to test the efficacy and safety of this vaccine candidate in protecting people again COVID-19 [39].

There are over a 100 vaccines being developed world wide and at least 30 clinical attempts in India, ICMR has joined force with Oxford university to create up to 60 million doses of potential vaccine, has effectively reported an exploration collaboration with Hyderabad based Bharat Biotech International Ltd (BBIL) to build up a COVID-19 vaccine. Additionally, the serum Institute of India (SII) which is the world's biggest creator of antibody vaccine by volume, has banded together with Oxford university to produce up to 60 million doses of vaccine.

In a recent studies, it was recognized that monoclonal counter acting agents (CR3022) ties with the spike RBD of SARS-COV-2. This is likely because of the antibody's epitope not covering with the dissimilar ACE2 receptor-restricting them and CR3022 can possibly be developed as a therapeutic competition, alone or in combination with other killing antibodies for the prevention and management of novel COVID-19.

\section{Conclusion}

In the face of a pandemic, the rapid development, deployment of diagnostic tools, drugs, and vaccine are critical. we carried out a systemic literature search using the web resources such as Google scholar, MEDLINE, Embase etc. Rigorous and adequate clinical trails for drug safety and effectiveness in randomized, controlled trails remain fundamental measures to protect the public from days that are ineffective, unsafe, or both some available candidate drugs targeting different levels of human response to COVID-19 
like Interferon, RNA dependent RNA polymerase may improve the clinical outcomes of critical COVID-19 patients encouraged the different diagnostic tests tools like RT-PCR, LAMP for identification of virus in COVID-19 patients. As no effective treatment against SARSCOV-2 is currently available, the best action is to develop vaccine to prevent the infection, therefore, considerable efforts should be given to limit or hinder the spread of the virus. Strong international coordination and collaboration among studies, pharmaceutical sectors, government bodies, regulatory departments are needed to ensure the promising treatment or vaccine can be manufactured and supplied successfully not only the treatment of the COVID-19 but also created devastating social, political, encomic threats. It is time for us to work together, share experience and move forward to fight against Pandemic COVID-19.

\section{Bibliography}

1. Muhammad Adnan Shkhana., et al. "COVID-19 infection: origin, transmission, and characteristics of human corona viruses". Journal of Advanced Research 24 (2020): 91-98.

2. WHO Novel corona virus situation dashboard. Geneva, Switzerland: WHO (2020).

3. Wu D., et al. "The SARS-COV-2 outbreak: What we know". International Journal of Infectious Diseases 94 (2020): 44-48.

4. 2019 Novel corona virus (2019-nCoV)". Centres for Disease Control and Prevention (2020).

5. Geller C., et al. "Human corona viruses: insights into environmental resistance and its influence on the development of new antiseptic strategies". Viruses 4.11 (2012): 3044-3068.

6. Luk HK., et al. "Molecular epidemiology, evolution and psychology of SARS coronavirus". Infection, Genetics and evolution 71 (20119): 21-30.

7. Coronavirus in viral zone.expasy.org/785 (2019).

8. Cascella M., et al. "Napoli RD: Features, evaluation and treatment coronavirus (COVID-19)". Statpearls Publishing, Treasure Island, FL (2020).

9. Maier H., et al. "Coronavirus: methods and protocols". Coronavirus Method Protac (2015): 1-282.

10. Li X., et al. "Molecular Immune Pathogenesis and Diagnosis of COVID-19". Journal of Pharmaceutical Analysis 19 (2020): 1-7.

11. KWOK YL., et al. "Face touching: a frequent habit that has implications for hand hygiene". American Journal of Infection Control 43 (2015): 112-114.
12. To KK., et al. "Consistent detection of 2019 novel corona virus in saliva”. Clinical Infectious Diseases (2020).

13. Amber Father., et al. "Corona various disease (COVID-19). Implications for clinical”. Dental care JOE 46.5. P584-595.

14. Van Boheemen., et al. "Genomic characterization of newly discovered corona virus associated with acute respiratory distress syndrome in humans". M Bio 3.6 (2012): e00473-e512.

15. VS Raj., et al. "Dipeptidyl peptidase 4 is a functional receptor for the emerging human corona virus-EMC". Nature 495.7440 (2013): 251-254.

16. Bertram I., et al. "Cleavage and activation of the severe acute respiratory syndrome corona virus spike protein by human airway tryspin-like protease". Journal of virology 85.24 (2011): 13363-13372.

17. X Xu., et al. "Evolution of the novel corona virus from the ongoing Wuhan outbreak and modeling of its spike protein for risk of human transmission". Science China Life Sciences 63.3 (2020): 457-460.

18. Shereen MA., et al. "COVID-19 Infection: origin, Transmission and characteristics of Human Coronavirus" 24 (2020): 91-98.

19. Maier HJ., et al. "Coronavirus: methods and protocols, coronavirus method protective” (2015): 1-282.

20. http://www.BBC.com/future/article/20200317-covid19-how-long-does-the-coronavirus-last-on-surface

21. Ahmed., et al. "A review of COVID-19 (coronavirus disease-2019) diagnosis, treatment and prevention".

22. Signal T. "A Review of coronavirus diseases-2019 (COVID-19)". Indian Journal of Pediatric 87.4 (2020): 281-286.

23. https://www.IAEA.org/newscenter/news/how-is-the-covid19-virus-detected-using-real-time-rt-pcr

24. Khan., et al. "COVID-19: An overview”. WJPR 9 (2020): 18101827.

25. Mile Green., et al. "What tests could potentially be used for the Screening, diagnosis and monitoring of COVID-19" (2020).

26. Micheal J., et al. "Laboratory diagnosis of emerging human corona virus infections".

27. Maharshi Malakar. "Coronavirus- A review article". Acts scientific Dental Sciences 4.5 (2020): 10-12. 
28. BX Wang E.N Fish editors Global virus outbreaks: Interferon as 1st responder seminars in Immunology Elsevier (2019).

29. M Wang., et al. "Remdesivir and chloroquine effectively inhibit the recently emerged novel corona virus (2019-nCoV) in-vitro". Cell Research 1-3 (2020).

30. ML Holshue., et al. "First case of 20919 novel corona virus in the United States". The New England Journal of Medicine (2020).

31. VK Derebail., et al. "ANCA-associated Vassilitish refining therapy with plasma exchange and glucocorticoids". The New England Journal of Medicine (2020).

32. White NJ. et al. “Malaria”. Lancet 383.9918 (2014): 723-735.

33. Vincent MJ., et al. "Chloroquine is a potent inhibitor of SARS corona virus infection and spread". Virology Journal 2 (2005): 69.

34. Kapoor KM and Kapoor A. "Role of chloroquine and Hydroxy chloroquine in the treatment of COVID-19 Infection-A systematic literature Review". (2020).

35. Ghosh. "Benefit over risk of using chloroquine and Hydroxy chloroquine in COVID-19 patients". World Journal of Pharmaceutical Research 9.5 (2020): 772-777.

36. Interferon therapy may speed recovery from COVID-19 Medscape (2020).

37. Remedesvir shortness COVID-19 time to Recovery in published study-Medscape (2020).

38. Yeming Wang., et al. "Remdesivir in adults with severe COVID-19: a randomised, double-blind, placebo-controlled, multi centre trail”. The Lancet 395.10236 (2020): P1569-1578.

39. Beigel J and Bray M. "Current and future antiviral therapy of severe seasonal and avian influenza". Antiviral Research 78.1 (2008): 91-102.

40. Glenmark to commence new phase 3 clinical trail on combination of two antiviral drugs favipiravir and umifenovir in hospitalized patients of moderate COVID-19 in India. PR News.

41. Glenmarklaunches. COVID-19 drug in India after DCGI approval COVID-19 drug in India after DCGI approval http://mumbaimirror. India times.com (2020).
42. Jiancheng Z., et al. "Current status of Potential therapeutic Candidates for the COVID-19 Crisis, Brain, Behavior, and Immunity".

43. Hung FT., et al. "A Review of SARS-COV-2 and the ongoing trials". International Journal of Molecular Sciences 21 (2020): 2657.

44. Hsieh HP and Hsu JT. "Strategies of development of antiviral agents directed against influenza virus replication". Current Pharmaceutical Design 13.34 (2007): 3531-3542.

45. Jonathan Grein., et al. "Original Article compassionate use of Remdesivir for patients with Severe COVID-19". The New England Journal of Medicine 382 (2020): 2327-2336.

46. Dayal D and Gupta S. "Connecting BCG vaccination and COVID-19: Additional Data”. Med Rxiv (2020).

47. http://www.theHindu.com/Sci-tech/Science/inactivatedprcovacc-vaccine-found-safe-efficacious-in-animal-study/article

48. Shine., et al. "CORONAVIRUS (COVID-19): Clinical features, diagnosis and treatment" 9 (2020).

49. Huang C., et al. "Clinical features of patients infected with 2019 novel coronavirus in Wuhan, China”. Lancet 395 (2020): 49740.

50. W Guan., et al. "Clinical characteristics of Coronavirus Diseases 2019 in China”.

51. Richman DD., et al. Clinical virology, $4^{\text {th }}$ edition. Washington: Asm Press (2016).

52. Garner JS., et al. "CDC definitions of nosocomial infections, 1988". American Journal of Infection Control 16 (1988): 128140.

\section{Assets from publication with us}

- Prompt Acknowledgement after receiving the article

- Thorough Double blinded peer review

- Rapid Publication

- Issue of Publication Certificate

- High visibility of your Published work

Website: www.actascientific.com/

Submit Article: www.actascientific.com/submission.php

Email us: editor@actascientific.com

Contact us: +919182824667 